\title{
Accidental self-insertion of an intrauterine contraceptive device into the bladder
}

\section{Chandrasiri $\mathrm{MD}^{\mathrm{a}}$, Wijeyarathna $\mathrm{SN}^{\mathrm{b}}$, Abeygunasekera $\mathrm{AM}^{\mathrm{c}}$ \\ Colombo South Teaching Hospital, Kalubowila, Sri Lanka.}

Key Words: Self-Insertion, IUCD, Bladder

\section{CASE REPORT}

A 20-year old mother of one child had an intrauterine contraceptive device (IUCD) inserted by a primary care medical doctor. Few days later her husband complained of discomfort during coitus and the woman removed the IUCD by herself. Following coitus, due to the fear of another pregnancy she self inserted the IUCD. Few days later she developed dysuria and suprapubic pain. As the symptoms were persisting even after two days, she sought medical advice. She did not have haematuria or difficulty in passing urine. A transvaginal ultrasound scan could not locate the device in the uterine cavity, but showed the IUCD freely floating inside the bladder. X-ray pelvis showed the IUCD in the region of the bladder. (Fig 1)

A cystoscopy showed the floating IUCD in the bladder, with no features of perforation or migration. It was retrieved with ease by grasping forceps (Fig 2).

\section{DISCUSSION}

Foreign bodies in the bladder can be due to self-insertion, migration from adjacent organs (uterus) and by iatrogenic causes. Among commonly self inserted objects, cotton swabs, tampons, paper clips, grass leaves, and plastic beans are reported in literature and are mostly related to acts of sexual gratification. ${ }^{1}$ Transmigration of IUCD from the uterine cavity to surrounding pelvic organs (bladder, pelvic colon) and retroperitoneal space has been

a Registrar in Obstetrics \& Gynaecology, Colombo South Teaching Hospital, Sri Lanka

${ }^{b}$ Senior Registrar in Urology, Colombo South Teaching Hospital, Sri Lanka

${ }^{c}$ Urological Surgeon, Colombo South Teaching Hospital Sri Lanka

Correspondence: Dr. Manoj D Chandrsiri, MBBS $M D$

Email-manojdc1980329@gmail.com

Competing interests: The authors report no conflict of interest



Fig $1 \mathrm{X}$ ray showing the $I U C D$ in the pelvis

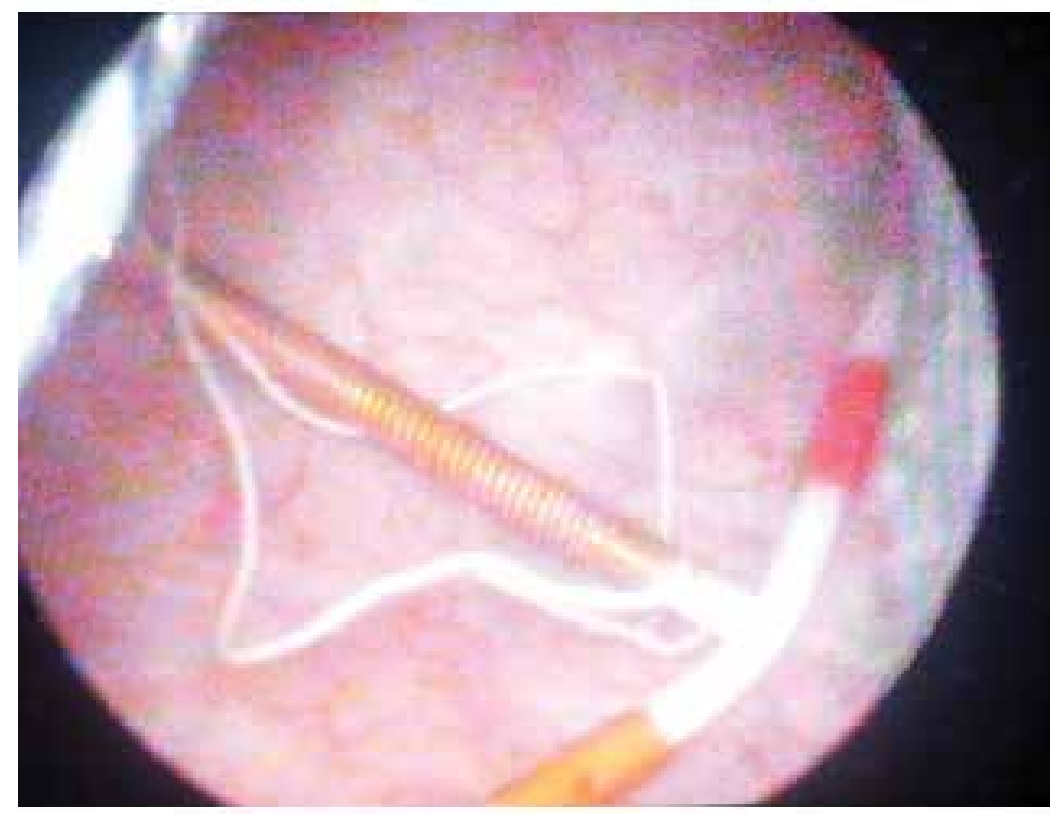

Fig 2 Cystoscopy view of the IUCD inside the bladder 
reported and is well known. ${ }^{2,3}$ Accidental primary placement of IUCD is rarely reported. ${ }^{4}$ Accidental self-insertion of an IUCD into the bladder via the urethra is unreported. Although the short female urethra could provide easy access to the bladder for foreign body placement, the extended limbs of the IUCD makes it less likely to be accidentally inserted to the bladder via the urethra. Short duration of few days makes migration unlikely in this patient. Discomfort to the male partner during coitus due to long trailing threads of IUCD is well known and the remedy is to cut the threads shorter. Women should be advised to seek medical assistance for problems related to the IUCD and should be discouraged to manipulate the IUCD by their own.

\section{REFERENCES}

1. Wachira K, Wipaporn P. Foreign Bodies in the Female Urinary Bladder: 20-Year Experience in Ramathibodi Hospital. Asian Journal of Surgery 2008; 31: 130-3

2. Abeygunasekera A, Vithanachchi K, Jayasinghe R, Chamintha T. Lippes loop in the retroperitoneal space. The Galle Medical Journal 2007; 12: 67-8

3. Abeygunasekera A, Vithanachchi K, Jayasinghe R, Chamintha T. Lippes loop in the retroperitoneal space. The Galle Medical Journal 2007; 12: 67-8
4. Senanayake H, Fernando H. An intrauterine device in the bladder mimicking urinary tract infection 2104. Ceylon Medical Journal; 47(1): p.28.

5. Radhika AG et al. The Unbelievable Case of Primary Placement of IUCD in Urinary Bladder. EC Gynaecology 2015; 2.1: 117-122. 